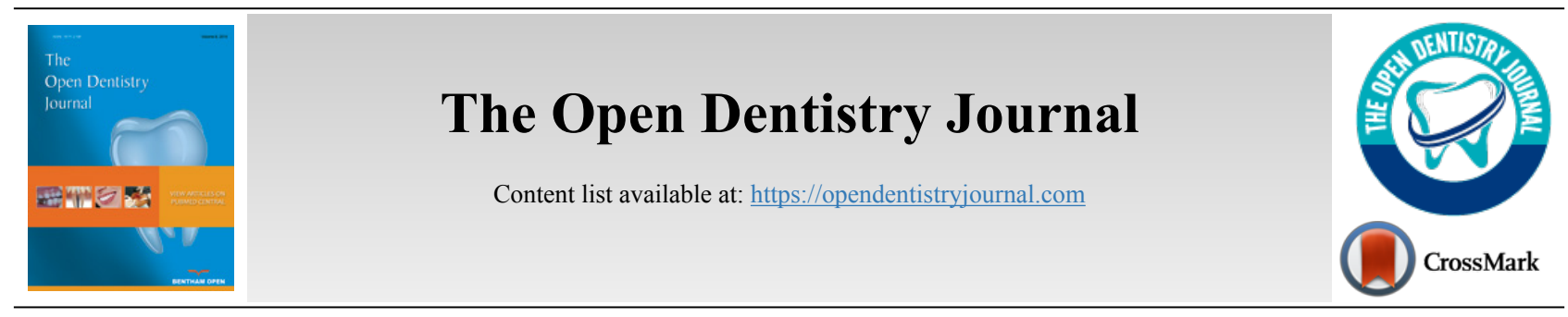

RESEARCH ARTICLE

\title{
Mandibular Gonial Angle Measurement as a Predictor of Gender-A Digital Panoramic Study
}

Eyas Abuhijleh,", Abdulhadi Warreth ${ }^{2}$, Mariam Qawadi $^{3}$, Einas Abdulrida ${ }^{4}$, Ahmed Radaideh $^{5}$, Amjad Al Taki $^{6}$, Ashok $^{2}$ Mathew ${ }^{7}$ and Sudhir Varma ${ }^{8}$

\author{
${ }^{\prime}$ Department of Orthodontics, College of Dentistry, University of Science \& Technology of Fujairah, Fujairah, United Arab Emirates \\ ${ }^{2}$ Department of Prosthodontics, University of Science \& Technology of Fujairah, Fujairah, United Arab Emirates \\ ${ }^{3}$ Department of Dentistry, Fujairah Dental Centre, Fujairah, United Arab Emirates \\ ${ }^{4}$ Department of Dentistry, Ajman University, Ajman, United Arab Emirates \\ ${ }^{5}$ Department of Statistics, University of Science \& Technology of Fujairah, Fujairah, United Arab Emirates \\ ${ }^{6}$ Department of Orthodontics, Private Practice, Dubai, United Arab Emirates \\ ${ }^{7}$ Department of Oral Radiology, University of Science \& Technology of Fujairah, Fujairah, United Arab Emirates \\ ${ }^{8}$ Department of Periodontics, University of Science \& Technology of Fujairah, Fujairah, United Arab Emirates
}

\begin{abstract}
:
Objective:

The present study is intended for properly assessing, comparing, and evaluating the contemporary measurements of gonial angle using digital panoramic radiography. In addition, this research evaluates the importance of mandibular gonial angle in gender determination.

Materials and Methods:

Technically, this is a retrospective cross-sectional study, where the study sample was composed of 590 (295 males and 295 females) patients undergoing digital panoramic radiography in the College of Dentistry in University of Science \& Technology of Fujairah, Fujairah, UAE . These patients had been prescribed panoramic radiographs based on different factors. As a generally adopted procedure, bilateral gonial angle measurements were carried out, results were recorded, and their predictability as a determinant of gender was assessed. ANOVA and t-test
\end{abstract} procedures were utilized for statistical analysis of the collected data.

Results:

The analysis of the present study confirmed a statistically significant difference between the right and left sides of the gonial angle in both genders. Further, the mean comparison exposed a variation between males and females, based on gonial angle values; females have a statistically significant higher mean angle values than males. Based on the analysis, the present study concludes that this difference between males and females from both sides suggests that the gonial angle helps in sex identification.

Conclusion:

It has been concluded that gender significantly influences the gonial region and has great potential to be used as a forensic tool in gender determination. Digital panoramic radiography is a good study tool and it can be used to determine the morphology of the mandible.

Keywords: Forensic dentistry, Gonial angle, Digital panoramic radiography, Gender prediction, Mandibular measurements, Random sampling procedure.

\begin{tabular}{|c|c|c|c|}
\hline Article History & Received: July 23, 2019 & Revised: September 18, 2019 & Accepted: October 20, 2019 \\
\hline
\end{tabular}

\section{INTRODUCTION}

In order to calculate age and recognize gender from the remains of human beings, accurate measurement and assess-

\footnotetext{
* Address correspondence to this author at Department of Orthodontics, College of Dentistry, University of Science \& Technology of Fujairah, P.O. Box. 2202, Fujairah, UAE., Tel: 0097192023604, Email: eyas97us@yahoo.com
}

ment of gonial angle values are required. Assessment of the anatomic gonial angle values according to age and gender has been analyzed before [1 - 10] as panoramic radiography (orthopantomography), a useful tool to measure the gonial angle [11 - 14] that offers similar results to lateral radiography [11]. 
However, previous studies on the current area of interest show mixed results as some of the studies [1, 15 - 17] suggest that gonial angle values can be used for determining age and gender, while some $[6,18,19]$ hold the idea that there is no statistically significant relationship between gonial values, age, and gender.

For the proper assessment of the mandibular and maxillary vital structure, practitioners most commonly and frequently advise panoramic radiographs (OPGs). This is considered the all-inclusive approach for imaging the number of different dental disorders in one film. It is authentic and a higher degree of prescription suggests that it can be successfully used for studying any morphological variations that are normally observed with changes in ages and has a correlation with gender. If the head positioning is kept constant and standardized, then a suitable duplicability in terms of vertical and angular variables for group comparisons is obtained [20 - 23]. Furthermore, it has been documented in the earlier studies that irrespective of the fact that the horizontal measurement is not much reliable, angular measurement is still carried out in the OPG process with significant reliability.

Because the left side and right side of our body play different roles, this study proposes the hypothesis that the right side gonial angle is significantly different from the left, further; there is a different type of correlation between gender and each side. To evaluate this relationship, a retrospective crosssectional study was carried out of panoramic radiography patients visiting the dental clinic of the University of Science and Technology of Fujairah. Digital panoramic radiographs were traced and evaluated in order to support the research. The study was conducted to better understand the alteration in the gonial region to correlate with gender determination.

\section{MATERIALS AND METHODS}

To conduct the current study, we selected the College of Dentistry, University of Science \& Technology of Fujairah, Fujairah, United Arab Emirates. Using a simple random sampling procedure, a total of 590 digital panoramic radiographs from the Asian patient's database stored at the Department of Oral and Maxillofacial Radiology were selected. These patients were visiting the dental clinic in University of Science \& Technology of Fujairah and thus were evaluated and included in the study. A general consent form was signed by all the participants of the study, which indicates their approval as their information might be used in the clinical research projects. Based on gender, the study sample was categorized into two groups i.e. 295 males (with an average age of 37.4 with SD 10.3) and 295 females (with an average age of 32.9 with SD 10.7) (Table 1). Having 590 subjects delivered greater than $86 \%$ power of the sample to detect the differences between male and female.

All the panoramic radiographic images were acquired using Planmeca ProMax ${ }^{\circledR}$ 3D Max panoramic machine (Planmeca Oy, Helsinki, Finland). Exposure parameters were ranging from $64-68 \mathrm{kVp}, 6.3-10 \mathrm{~mA}$, and $0.19 \mathrm{~s}$ according to the patient's age and size. The adopted inclusion criterion of the present study is significantly matched by all the selected images for analysis.

\subsection{Inclusion Criteria}

- Those images were selected that were with high panoramic standard quality and were free from any kind of exposure and positioning errors.

- If all factors and parameters are clearly visible on the image obtained through the digital panoramic radiographic process and that for gonial angle a clear tracing can be observed.

\subsection{Exclusion Criteria}

- Individuals giving a history of orthognathic surgery.

- Individuals with the Temporomandibular Joint Disorder (TMD).

- $\quad$ Syndromes affecting the face/jaw.

- Patient with gross facial asymmetry.

- Any type of general and domestic syndromes that could possibly influence the development of the craniofacial region.

- Any history of facial trauma.

- History of any other major surgery and/ or radiotherapy related to head and neck.

- Mixed dentition.

- Evident radiographic error.

Using the JPG file format, all the required digital panoramic images were saved and for linear and angular measurement they were exported to Planmeca Romexis ${ }^{\circledR}$ software. Following the well-developed procedure, panoramic landmarks were located, identified, and marked on the selected radiograph using the calibration. A single examiner determined the gonial angle measurements and they were undertaken as described by Upadhyay et al. 2012 [24] measuring between 2 tangents from the gonion; whereas the one campaigning overbearingly with the posterior edge of the mandibular ramus while the other anteriorly along the inferior edge of the body of the jaw bone (Fig. 1). For obtaining an average value, a consensual measurement was performed both for the right and left-hand sides of the radiograph.

\section{RESULTS}

\subsection{Statistical Analysis}

A type of pilot study prior to collecting data for the whole sample was carried out, in which the reliability of the measure was tested by an expert through data from 25 subjects. Following this, data from the targeted study sample were collected and coded in Statistical Software for Social Sciences (IBM SPSS Inc, Chicago, III) for further analysis. One sample and paired sample t-test were carried out to determine the differences between the right and left sides of the gonial angle in both genders and to determine the differences between the same sides of the gonial angle in both genders. The study group consisted of 590 digital panoramic radiographs (295 males and 295 females). The reliability analysis for all the dependent variables under study was calculated by using Cronbach's Alpha, and in our case, it was equal to 0.843 , which can be considered as good. 
Table 1. Descriptive statistics: The average age for males, females and overall.

\begin{tabular}{|c|c|c|c|c|c|c|c|c|}
\hline \multicolumn{2}{|c|}{ Gender } & N & Range & Min. & Max. & \multicolumn{2}{c|}{ Mean } & Std. Deviation \\
\cline { 3 - 9 } \multicolumn{2}{|c|}{} & Statistic & Statistic & Statistic & Statistic & Statistic & Std. Error & Statistic \\
\hline F & Age & 295 & 44 & 16 & 60 & 32.91 & .781 & 10.676 \\
\hline M & Age & 295 & 49 & 16 & 65 & 37.41 & .565 & 10.296 \\
\hline Overall & Age & 590 & 49 & 16 & 65 & 35.79 & .467 & 10.645 \\
\hline
\end{tabular}

Table 2. One-sample statistics - Descriptive statistics.

\begin{tabular}{|c|c|c|c|c|c|}
\hline \multicolumn{2}{|c|}{ Dependent Variable } & \multirow{2}{*}{ Mean } & \multirow{2}{*}{ Std. Error } & \multicolumn{2}{c|}{ 95\% Confidence Interval } \\
\cline { 5 - 6 } & & 123.198 & 0.315 & Lower Bound & Upper Bound \\
\hline \multicolumn{2}{|c|}{ Right Side (590) } & 124.347 & 0.307 & 122.581 & 123.816 \\
\hline \multicolumn{2}{|c|}{ Left Side (590) } & 122.2 & 0.445 & 123.745 & 124.95 \\
\hline \multirow{2}{*}{ Right Side (295) } & Male & 124.197 & 0.445 & 123.326 & 123.074 \\
\cline { 2 - 5 } & Female & 123.403 & 0.434 & 122.551 & 125.07 \\
\hline \multirow{2}{*}{ Left Side (295) } & Male & 125.292 & 0.434 & 124.439 & 12.255 \\
\cline { 2 - 5 } & Female & & & \\
\hline
\end{tabular}

Table 3. Paired samples test: The difference between the right and left side of the gonial angle in both genders.

\begin{tabular}{|c|c|c|c|c|c|c|c|c|c|}
\hline \multirow{3}{*}{\multicolumn{2}{|c|}{ Gender }} & \multicolumn{5}{|c|}{ Paired Differences } & \multirow{3}{*}{ t-Value } & \multirow{3}{*}{ Differences } & \multirow{3}{*}{$\begin{array}{c}\text { Significant } \\
\text { Difference } \\
\text { (2-tailed) }\end{array}$} \\
\hline & & \multirow[t]{2}{*}{ Mean } & \multirow[t]{2}{*}{ Std. Deviation } & \multirow[t]{2}{*}{$\begin{array}{l}\text { Std. Error } \\
\text { Mean }\end{array}$} & \multicolumn{2}{|c|}{$\begin{array}{l}\text { 95\% Confidence Interval of the } \\
\text { Difference }\end{array}$} & & & \\
\hline & & & & & Lower & Upper & & & \\
\hline Male & $\begin{array}{l}\text { Right side - Left } \\
\text { side }\end{array}$ & -1.203 & 4.801 & .280 & -1.754 & -.653 & -4.305 & 294 & .000 \\
\hline Female & $\begin{array}{l}\text { Right side - Left } \\
\text { side }\end{array}$ & -1.095 & 6.541 & .381 & -1.844 & -.345 & -2.875 & 294 & .004 \\
\hline
\end{tabular}

Table 4. Male \& female ANOVA for the left side and the right side measurements.

\begin{tabular}{|c|c|c|c|c|c|c|}
\hline- & - & Sum of Squares & Df & Mean Square & $\mathbf{F}$ & Sig. \\
\hline \multirow[t]{3}{*}{ Left Side } & Between Groups & 525.846 & 1 & 525.846 & 9.471 & .002 \\
\hline & Within Groups & 32647.925 & 588 & 55.524 & - & - \\
\hline & Total & 33173.771 & 589 & - & - & - \\
\hline \multirow[t]{3}{*}{ Right Side } & Between Groups & 588.002 & 1 & 588.002 & 10.072 & .002 \\
\hline & Within Groups & 34325.797 & 588 & 58.377 & - & - \\
\hline & Total & 34913.798 & 589 & - & - & - \\
\hline
\end{tabular}

Table 2 documents the descriptive statistics for the study sample. Data were presented as a number of sample, mean, standard error, and a $95 \%$ confidence interval of the mean of both right and left sides of the gonial angle for each gender.

The average of the gonial angle for the right side and left side for all the subjects was 123.198 and 124.347 , respectively, precisely the average $\mathrm{R}$ side for the male was 122.2 while for the female was 124.197 , also the average for the L side was 123.403 for the male and 125.292 for the female. This shows that the $\mathrm{R}$ side and the $\mathrm{L}$ side gonial angle for the female was greater than the male in both cases.

Based on the gender, Paired sample t-test was used to compare the mean value for both sides of the gonial angle (Table 3). A comparison between the right and the Left side gonial angles was performed, and it was found that there was a statistically significant difference between the two sides in both male and female. That is why we cannot depend on the average of the right and left side for each gender.

In consequence, we came up with an idea to compare the right side gonial angle of the female with the right side of the male and do the same for the left side gonial angle (Table 4).

The analysis of variance ANOVA table gave the above results for left side and right side measurements for both groups; the outputs suggest that there is a statistically significant difference between groups with an exact probability value of 0.002 . This leads us to conclude that with a $95 \%$ confidence interval if a measurement of the Left side is obtained in the range of 122.48 and 124.33 then the participant must be male. Similarly, an interval obtained between 124.51 and 126.07 with a confidence level of $95 \%$ will suggest a 
female. Further, an interval obtained between 121.28 and 123.12 with a confidence level of $95 \%$ for the right side will suggest that the participant is male and otherwise it must be female.

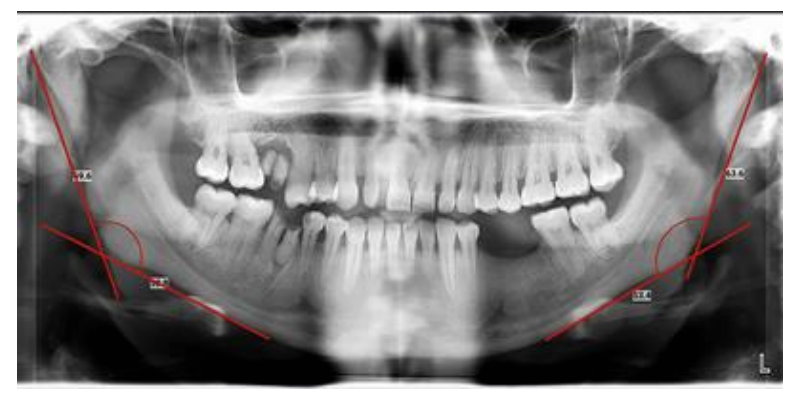

Fig. (1). Measurement of the gonial angle on the digital panoramic radiograph.

\section{DISCUSSION}

A critical review of the previous literature on the current area of interest revealed that a number of studies have been conducted for analyzing the difference between the values of male and female gonial angles; however, very insignificant research has been carried out regarding analyzing the gender assessment on the basis of values obtained for the gonial angle. This study extends that the existing morphology of the jaw bones can be used for the categorization of genders.

The analysis and study of sex determination are simultaneously important for forensic investigations and for regional differences and population history [25]. In addition to that, determination of the correct age has become an important duty of medicolegal officers in light of the contemporary increasing crimes.

It has been observed that in the entire human body, the two highly sexual dimorphic parts are mandibular condyle and ramus because these are the parts that experience maximum morphological changes in size and restriction during the life span [26]. Based on the above analysis, for the determination of gender, the current study has selected the mandibular gonial angle measurement procedure.

The present study was attempted for assessing the importance of mandibular gonial angle as an aid in sex determination. The study sample was composed of 590 OPGs among which 295 were male and 295 female participants. Based on the fact that OPGs have been accepted as an authentic and reliable procedure for the measurement of angular parameters, this procedure has been selected prior to lateral cephalograms. Similarly, it has been proved that it is not affected by the magnification error and by the coinciding disadvantage of the lateral cephalograms. Further, regardless of its untrustworthiness in horizontal measurement, angular measurements can be carried out with high accuracy and reliability in OPG. Similarly, it has also been proved that an insignificant slight misalignment of the head, which is frequently observed in daily life, cannot significantly influence vertical calculations in the posterior mandible or maxilla, or in the anterior mandible, and minor anteroposterior changes and inclines are linked with a difference of less than $2 \%$ for mandibular measurements in the vertical plane [27]. Consequently, we can conclude that the method used in the present study is considered reliable for the determination of the gonial angle. Moreover, the comparison can be made easy for the left and right sides of the parameters.

It is important to mention that the differences in measurements were very small but were statistically significant. This may be due to the alterations in the making of the $\mathrm{x}$ rays or in the manual measurements, which may reduce the credibility of the measurements

Based on gender differences, the present study confirmed a statistically significant difference in gonial angles. The study explicitly revealed that females had statistically significantly higher gonial angles than males. The gender differences were statistically significant in the gonial angle where males have a lower value than females. Findings of the current study are in line with the results of the previous relevant studies $[1,16,28$, 29] which reach the same conclusion; females have a higher gonial angle, this specific result might be due to the remarkable impact of masticatory forces [1]. Particularly, it is observed that an individual with relatively higher masticatory forces has a small gonial angle; men mostly have greater masticatory force than women [30]. On average, bones in male skeleton are relatively thick and large than females; however, this is not universal, because a number of factors other than gender, such as better nutrition and heavy physical activity, determine bone size and thickness [9]. This might also be due to gender hormonal differences; testosterone in males and estrogen in females affect bone metabolism, thereby showing visible changes in radiographs, and contributing to the development of craniofacial morphologic differences between genders. On average, males have greater masticatory force than females which influences the bone size. Literature suggests that muscular tension is the most important determinant of bone formation and in mandible, the mixture of elevating muscles during masticatory movement exerts tension throughout the ramus [31].

Conversely, other researchers found that males showed statistically significant higher mean gonial angle values than females as mentioned in a previous study [32], and others did not find any statistically significant differences between both sexes $[27,33]$. A study found that females have a downward and backward rotation in the mandible and males have a forward rotation in the mandible. Hence, the gonial angle values in females are higher than in males. Two factors, such as gender hormonal differences that affect bone metabolism or mastication muscles might be responsible for this difference in the gonial angles. The present study confirmed a significant difference between right and left gonial angles in both sexes, which proved the intrinsic nature of the irregularity of the human mandible. The findings are further supported by the fact that the jaw bone could be physiologically asymmetric, in case malformation is not found or even if the skull base is asymmetric.

The analysis suggests that the final physical design of any completely developed mandible is observed due to the genetic determination, which exposes them as a result of the working 
environment. Further, the multifaceted design of the jaw bone suggests that it can be used for a number of purposes.

\section{CONCLUSION}

Human identification has always been a significantly important task for society. Summing up the above discussion revealed that the outcomes of the current work are in line with the previous relevant literature; using values of gonial angles is significantly important and helpful in the determination of gender. Further, this can be equally used as an important forensic tool in investigations regarding gender identification. The study explicitly revealed that females had statistically significantly higher gonial angles than males. There are two factors responsible for this difference in gonial angles. The first one is gender hormonal differences and this can be described in terms of different concentrations and secretion of different hormones to illustrate that estrogen affects bone metabolism in females while in males, testosterone is the effective factor in bone remodeling. The second factor is that mastication muscles might be responsible for this difference in gonial angles; this can be described as subjects with maximum masticatory force have a small gonial angle since powerful muscles will bend the lower border of the mandible against the ramus, and on average, men have greater masticatory force than women. In this study, we found that there is a significant difference between the right gonial angles of females and the right and also the left gonial angles of males and this can be considered as a determinant for gender.

\section{ETHICAL APPROVAL AND CONSENT TO PARTICIPATE}

This study was approved by Ethical committee of University of Science \& Technology of Fujairah, Fujairah, UAE. (Reference Number GDF-2017/18-03-S).

\section{HUMAN AND ANIMAL RIGHTS}

No animals were used in this research. All research procedures on humans were followed in accordance with the ethical standards of the committee responsible for human experimentation (institutional and national), and with the Helsinki Declaration of 1975, as revised in 2013. (http://ethics.iit.edu/ecodes/node/3931)

\section{CONSENT FOR PUBLICATION} form.

All the participants of the study signed a general consent

\section{AVAILABILITY OF DATA AND MATERIALS}

The datasets analyzed during the current study are available from the corresponding author upon request.

\section{FUNDING}

\section{None.}

\section{CONFLICT OF INTEREST}

The authors declare no conflict of interest, financial or otherwise.

\section{ACKNOWLEDGEMENTS}

We would like to acknowledge Mr. Michael Clarito, Radiographic Technician at University of Science \& Technology of Fujairah, Fujairah, United Arab Emirates for his assistance in accessing the panoramic radiographs records for assessment and evaluation.

\section{REFERENCES}

[1] Bhardwaj D, Kumar JS, Mohan V. Radiographic evaluation of mandible to predict the gender and age. J Clin Diagn Res 2014; 8(10): ZC66-9.

[http://dx.doi.org/10.7860/JCDR/2014/9497.5045] [PMID: 25478451]

[2] Afsar A, Haas DA, Rossouw PE, Wood RE. Radiographic localization of mandibular anesthesia landmarks. Oral Surg Oral Med Oral Pathol Oral Radiol Endod 1998; 86(2): 234-41.

[http://dx.doi.org/10.1016/S1079-2104(98)90131-7] [PMID: 9720101]

[3] Ashkenazi M, Taubman L, Gavish A. Age-associated changes of the mandibular foramen position in anteroposterior dimension and of the mandibular angle in dry human mandibles. Anat Rec (Hoboken) 2011; 294(8): 1319-25.

[http://dx.doi.org/10.1002/ar.21429] [PMID: 21714109]

[4] Gungor K, Sagir M, Ozer I. Evaluation of the gonial angle in the Anatolian populations: From past to present. Coll Antropol 2007; 31(2): $375-8$.

[PMID: 17847912]

[5] Uthman AT. Retromolar space analysis in relation to selected linear and angular measurements for an Iraqi sample. Oral Surg Oral Med Oral Pathol Oral Radiol Endod 2007; 104(4): e76-82.

[http://dx.doi.org/10.1016/j.tripleo.2007.05.013] [PMID: 17703969]

[6] Ișeri H, Kişnişci R, Altuğ-Ataç AT. Ten-year follow-up of a patient with hemifacial microsomia treated with distraction osteogenesis and orthodontics: An implant analysis. Am J Orthod Dentofacial Orthop 2008; 134(2): 296-304.

[http://dx.doi.org/10.1016/j.ajodo.2006.12.014] [PMID: 18675213]

[7] Gamba TdeO, Alves MC, Haiter-Neto F. Mandibular sexual dimorphism analysis in CBCT scans. J Forensic Leg Med 2016; 38: 106-10.

[http://dx.doi.org/10.1016/j.jflm.2015.11.024] [PMID: 26773251]

[8] Rösing FW, Graw M, Marré B, et al. Recommendations for the forensic diagnosis of sex and age from skeletons. Homo 2007; 58(1): 75-89

[http://dx.doi.org/10.1016/j.jchb.2005.07.002] [PMID: 17306261]

[9] Al-Shamout R, Al-Habahbah A. Age and gender differences in gonial angle, ramus height and bigonial width in dentate subjects. Pak Oral Dent J 2012; 32: 81-7.

[10] Rai B, Anand S, Jain R. Effect of age and sex: Antegonial and gonial notch of mandible. Internet J Biological Anthropol 2006; 1(1): 3.

[11] Zangouei-Booshehri M, Aghili H-A, Abasi M, Ezoddini-Ardakani F. Agreement between panoramic and lateral cephalometric radiographs for measuring the gonial angle. Iran J Radiol 2012; 9(4): 178-82. [http://dx.doi.org/10.5812/iranjradiol.8444] [PMID: 23407613]

[12] Khetani MA, Collett BR, Speltz ML, Werler MM. Health-related quality of life in children with hemifacial microsomia: Parent and child perspectives. J Dev Behav Pediatr 2013; 34(9): 661-8. [http://dx.doi.org/10.1097/DBP.0000000000000006]

[PMID: 24213374]

[13] Bhuyan R, Mohanty S, Bhuyan SK, Pati A, Priyadarshini S, Das P. Panoramic radiograph as a forensic aid in age and gender estimation: Preliminary retrospective study. J Oral Maxillofac Pathol 2018; 22(2): 266-70.

[http://dx.doi.org/10.4103/jomfp.JOMFP_90_17] [PMID: 30158784]

[14] Sairam V, Potturi GR, Praveen B, Vikas G. Assessment of effect of age, gender, and dentoalveolar changes on mandibular morphology: A digital panoramic study. Contemp Clin Dent 2018; 9(1): 49-54. [PMID: 29599584]

[15] Huumonen S, Sipilä K, Haikola B, et al. Influence of edentulousness on gonial angle, ramus and condylar height. J Oral Rehabil 2010; 37(1): 34-8.

[http://dx.doi.org/10.1111/j.1365-2842.2009.02022.x] [PMID: 19912483]

[16] Abu Alhaija ES, AlBhairan HM, AlKhateeb SN. Mandibular third molar space in different antero-posterior skeletal patterns. Eur J Orthod 2011; 33(5): 570-6.

[http://dx.doi.org/10.1093/ejo/cjq125] [PMID: 21187531] 
[17] Leversha J, McKeough G, Myrteza A, Skjellrup-Wakefiled H, Welsh J, Sholapurkar A. Age and gender correlation of gonial angle, ramus height and bigonial width in dentate subjects in a dental school in Far North Queensland. J Clin Exp Dent 2016; 8(1): e49-54. [http://dx.doi.org/10.4317/jced.52683] [PMID: 26855706]

[18] Ohm E, Silness J. Size of the mandibular jaw angle related to age, tooth retention and gender. J Oral Rehabil 1999; 26(11): 883-91. [http://dx.doi.org/10.1046/j.1365-2842.1999.00464.x] [PMID: 10583739]

[19] Hassan AH. Mandibular cephalometric characteristics of a Saudi sample of patients having impacted third molars. Saudi Dent J 2011; 23(2): 73-80.

[http://dx.doi.org/10.1016/j.sdentj.2010.11.001] [PMID: 23960502]

[20] Singh B, Kahlon SS, Narang RS, et al. To assess the values of gonial and antegonial angle on panoramic radiograph and their role in the gender determination. J Dent Oral Health 2016; 2(4): 41

[21] Okşayan R, Aktan AM, Sökücü O, Haştar E, Ciftci ME. Does the panoramic radiography have the power to identify the gonial angle in orthodontics? Scientific World J 2012; 2012: 219708.

[http://dx.doi.org/10.1100/2012/219708] [PMID: 23365514]

[22] Tsatsoulis IN, Filippatos CG, Floratos SG, Kontakiotis EG. Estimation of radiographic angles and distances in coronal part of mandibular molars: A study of panoramic radiographs using EMAGO software. Eur J Dent 2014; 8(1): 90-4

[http://dx.doi.org/10.4103/1305-7456.126254] [PMID: 24966753]

[23] Al Taki A, Ahmed MH, Ghani HA, Al Kaddah F. Impact of different malocclusion types on the vertical mandibular asymmetry in young adult sample. Eur J Dent 2015; 9(3): 373-7.

[http://dx.doi.org/10.4103/1305-7456.163233] [PMID: 26430365]

[24] Upadhyay RB, Upadhyay J, Agrawal P, Rao NN. Analysis of gonial angle in relation to age, gender, and dentition status by radiological and anthropometric methods. J Forensic Dent Sci 2012; 4(1): 29-33. [http://dx.doi.org/10.4103/0975-1475.99160] [PMID: 23087579]

[25] Saini V. Metric study of fragmentary mandibles in a North Indian population. Bull Int Assoc Paleodont 2013; 7(2): 157-62.

26] Indira AP, Markande A, David MP. Mandibular ramus: An indicator for sex determination - A digital radiographic study. J Forensic Dent Sci 2012; 4(2): 58-62.

[http://dx.doi.org/10.4103/0975-1475.109885] [PMID: 23741142]

[27] Dutra V, Yang J, Devlin H, Susin C. Mandibular bone remodelling in adults: Evaluation of panoramic radiographs. Dentomaxillofac Radiol 2004; 33(5): 323-8

[http://dx.doi.org/10.1259/dmfr/17685970] [PMID: 15585810]

[28] Ghosh S, Vengal M, Pai KM, Abhishek K. Remodeling of the antegonial angle region in the human mandible: A panoramic radiographic cross-sectional study. Med Oral Patol Oral Cir Bucal 2010; 15(5): e802-7.

[http://dx.doi.org/10.4317/medoral.15.e802] [PMID: 20383108]

[29] Xie QF, Ainamo A. Correlation of gonial angle size with cortical thickness, height of the mandibular residual body, and duration of edentulism. J Prosthet Dent 2004; 91(5): 477-82.

[http://dx.doi.org/10.1016/j.prosdent.2004.02.020] [PMID: 15153856]

[30] Kumar MP, Lokanadham S. Sex determination \& morphometric parameters of human mandible. Int J Res Med Sci 2013; 1: 93-6. [http://dx.doi.org/10.5455/2320-6012.ijrms20130511]

[31] Bhardwaj D, Kumar JS, Mohan V. Radiographic evaluation of mandible to predict the gender and age. J Clin Diagn Res 2014; 8(10): ZC66-9.

[http://dx.doi.org/10.7860/JCDR/2014/9497.5045] [PMID: 25478451]

[32] Kharoshah MA, Almadani O, Ghaleb SS, Zaki MK, Fattah YAS. Sexual dimorphism of the mandible in a modern Egyptian population. J Forensic Leg Med 2010; 17(4): 213-5.

[http://dx.doi.org/10.1016/j.jflm.2010.02.005] [PMID: 20382358]

[33] Shahabi M, Ramazanzadeh BA, Mokhber N. Comparison between the external gonial angle in panoramic radiographs and lateral cephalograms of adult patients with Class I malocclusion. J Oral Sci 2009; 51(3): 425-9.

[http://dx.doi.org/10.2334/josnusd.51.425] [PMID: 19776510]

(C) 2019 Abuhijleh et al.

This is an open access article distributed under the terms of the Creative Commons Attribution 4.0 International Public License (CC-BY 4.0), a copy of which is available at: (https://creativecommons.org/licenses/by/4.0/legalcode). This license permits unrestricted use, distribution, and reproduction in any medium, provided the original author and source are credited. 